\title{
Utilization and Determinants of Postnatal Care Services in Ethiopia: A Systematic Review and Meta-Analysis
}

\author{
Eshetu E. Chaka ${ }^{1,2}$, Ahmed A. Abdurahman ${ }^{3}$, S. Nedjat ${ }^{1}$, R. Majdzadeh ${ }^{4 *}$
}

OPEN ACCESS

Citation: Eshetu E. Chaka, Ahmed A. Abdurahman, S. Nedjat, R. Majdzadeh. Utilization and Determinants of Postnatal Care Services in Ethiopia: A Systematic Review and Meta-Analysis. Ethiop J Health Sci. 2018;29(1):929.

doi:http://dx.doi.org/10.4314/ejhs.v29i1.16 Received: April 1, 2018

Accepted: June 11, 2018

Published: January 1, 2019

Copyright: (C) 2018 Eshetu E Chaka, et al. This is an open access article distributed under the terms of the Creative Commons Attribution License, which permits unrestricted use, distribution, and reproduction in any medium, provided the original author and source are credited.

Funding: Bona District Health Bureau and Abem private clinic.

Competing Interests: The authors declare that this manuscript was approved by all authors in its form and that no competing interest exists.

Affiliation and Correspondence:

${ }^{1}$ Department of Epidemiology and Biostatistics, School of Public Health, Tehran University of Medical Sciences International Campus (TUMS-IC), Tehran, Iran ${ }^{2}$ Department of Public Health, College of Medicine and Health Sciences, Ambo University, Ambo Oromia, Ethiopia

${ }^{3}$ Department of Community Nutrition, School of Nutritional Sciences and Dietetics, Tehran University of Medical Sciences International Campus (TUMS-IC), Tehran, Iran

${ }^{4}$ Department of Epidemiology and Biostatistics, School of Public Health, Knowledge Utilization Research Centre, Tehran University of Medical Sciences, Tehran, Iran *Email: rezamajdzadeh@gmail.com

\section{ABSTRACT}

BACKGROUND: Postnatal care use is vital in saving mother and newborn lives which is a continuum of care for maternal, neonatal and child health. This reviewaimed to determine the utilization and determinants of postnatal care use in Ethiopia.

METHODS: PubMed, Scopus, Web of Science, and Embase databases were searched on June 25, 2017. The study screening, data extraction and quality assessment were done independently by two reviewers. Effect sizes were pooled using a random-effects model.

RESULTS: Nine articles were included in the review. The pooled estimate for utilization of the service was 32\% (95\% CI: $21 \%$, 43\%). The pooled results of determinants of postnatal care use was statistically significant among those mothers who had ability to make decisions (1.89; 1.25, 2.54), had a history of antenatal care utilization $(2.55 ; 1.42,3.68)$, received more than two antenatal care visits $(1.84 ; 1.28,2.40)$, and received the service from skilled service provider $(3.16 ; 1.62,4.70)$. It was also found that mothers who gave birth in health faciliteis $(2.13 ; 1.14,3.12)$, had middle monthly income, richer, were from urban areas, and had knowledge of obstetric danger signs were significantly associated with increased odds of postnatal care use.

CONCLUSION: Utilization of the services is low in Ethiopia. Antenatal care utilization, skilled service provider, being from urban area and delivery in health facility had a significant effect on postnatal care utilization. More rigorous studies are needed to identify determinant with the causal association to postnatal care utilization. The review was registered on PROSPERO CRD42017060266.

KEYWORDS: Postnatal care, Utilization, Determinants, Ethiopia

\section{INRODUCTION}

Although the impressive progress gained for maternal and child health during the millennium development goals era, over 5.6 million women and babies died in 2015 due to complications related to pregnancy, birth or postnatal period (42 days after delivery). A large proportion of maternal and neonatal deaths occurred during the first 48 hours after delivery $(1,2)$. For example, the World Health Organization (WHO) reports have shown that some $50 \%$ of maternal deaths and $40 \%$ of neonatal deaths occur within 24 hours after birth

DOI: http://dx.doi.org/10.4314/ejhs.v28i5.16 
(3). Thus, prompt postnatal care (PNC) for the mother and the child is important to treat any complications arising from the delivery and to provide the mother with important health information.

According to WHO's definition, the postnatal period is at a time interval that starts from the birth of the baby to six consecutive weeks with the recommended time of visit, that is, 6 to 24 hours, 3 to 6 days and 6 weeks following childbirth (4). Safe motherhood program recommends that all women receive a check of their health within 2 days after delivery (5). Providing proper postnatal care services with skilled health personnel is an essential and key strategy to save the life of the mother and the newborn (6). Moreover, postnatal care services are a basic element of the continuum of care for maternal, neonatal and child health that decreases maternal and neonatal morbidity and mortality in developing countries $(7,8)$.

Many studies identified factors affecting postnatal care services utilization. They are antenatal care visit, delivery place, mother's education level, household wealth index, birth order and educational level of the partner (9-12).

Moreover, use untrained birth attendants, rural residence and lack of exposure to any media were identified risk factors of postnatal care services use. Additionally, knowledge about pregnancy-related complications, birth outcome and distance from a health facility were also reported as risk factors $(9,10)$.

Compared with other maternal and infant health services, the coverage for postnatal care tends to be relatively poor. Increasing such coverage has been highlighted as a priority. For example, in the Democratic Republic of Congo, $35 \%$ of women receive postnatal care (13); in Kenya, less than $20 \%$ women receive postnatal care whilein India $44 \%$ women receive postnatal care within 48 hours after birth (14). However, in Ethiopia, only $17 \%$ of women receive postnatal care which is far from $26 \%$ of deliveries that occurred in health facilities (2). Generally, despite the fact that PNC services are made accessible to nearly all villages at lower or no cost and its effectiveness to save maternity and newborn life coverage of postnatal, is still extremely low even for women who give birth in the health facility in Ethiopia (2).

Inadequate access to postnatal care services utilization is associated with factors at different levels. However, these associations have not been assessed systematically in Ethiopia. Therefore, we conducted a systematic review and meta-analysis of the relevant evidence to determine the utilization and the factors affecting postnatal care services in Ethiopia. This allows to inform policymaker, help strengthen the health system and access to and use of postnatal care services.

\section{MATERIALS AND METHODS}

This systematic review was performed by using a pre-specified protocol with the aim of reviewing the evidence that shows the prevalence and determinants of postnatal care services utilization in Ethiopia. It was registered with PROSPERO (\#CRD42017060266). Preferred Reporting Items for Systematic Reviews and Meta-Analyses (PRISMA) guidelines were followed in conducting the review and reporting the results of this systematic review and meta-analysis (15).

Search strategy: We performed a systematic and a comprehensive literature search of electronic bibliographic databases without any restriction to publication date, study design or language on March 25, 2017, through MEDLINE/PubMed, EMBASE, Web of Sciences, Scopus, and Grey literature databases. Our search strategy has included keywords, medical subject headings $(\mathrm{MeSH})$ terms, and exploded headings. The keywords found in the retrieved articles were fed back into the search strategy. We also performed hand search for reference lists of the articles found through the database search and included the articles relevant to our topic of review.

Identification and selection of studies: Studies comprised any published articles that assess determine factors affecting postnatal care utilization among mothers aged between 15-49 years in Ethiopia. The exclusion criteria included the following: 1) non-human studies; 2) reviews, case reports, conference abstract, and letters; 3) studies in which appropriate measures of association were not reported; 4) abstracts with no

DOI: http://dx.doi.org/10.4314/ejhs.v27i8.16 
more information or no full-text article; and 5) duplicate data. All studies that addressed determinants of postnatal care services utilization and reported appropriate measures of association determinants were included. No inclusion criteria with regard to study quality were used to present the total picture of the data available.

Data Collection and synthesis: Two independent reviewers (AAA and EEC) screened all articles retrieved through the search strategy by title and abstract for eligibility according to the inclusion and exclusion criteria. Whenever the abstract seemed relevant, a full-text assessment was done. Also, the full-text of appropriate trials retrieved and screening list was filled to choose the eligible articles. In addition, the two authors (AAA and EEC) performed the quality assessment of studies independently. In the case of disagreement, they resolved it by consensus.

Data extraction: Data extractions were performed through a standardized data extraction form that had been pilo-tested in random sample studies. Data were collected on first author's last name, year of publication, year of data collection, study setting (region and rural or urban), participants' age, study design, sample size,outcome definition, response rate, statistically significant determinants, adjusted Odds ratio or risk ratio (AOR or ARR), 95\% confidence interval, prevalence and covariance. Where results were published several times, the data were used only once. Uncertainties during the extraction process were resolved by joint discussions between the two reviewers. In the case of incomplete data, one attempt was made to contact the corresponding author by email. When there were no responses, we excluded the study or the parameter that was not available.

Study quality and risk of bias assessment: The scientific quality and strength of each selected/included study was assessed using the modified Newcastle-Ottawa Scale for nonrandomized studies $(16,17)$. The following parameters were assessed: sampling strategy, inclusion/exclusion criteria, sample size, sample representativeness, methods of data collection and adequacy of response rate (Table 1). The final scoring system comprised 10 criteria of rating different quality elements for each eligible articles out of 11 scores. The authors recommended scale weights for each element of the scoring system, as proposed in other meta-analyses. Studies were classified into three quality groups and labeled A if they managed to obtain 8-11 points, $B$ when 4-7 points were collected and $\mathrm{C}$ when they scored less than 4 points. Studies of high quality, with the less estimated risk of bias, were allocated to class ' $A$ ' and subsequently used in the sensitivity analyses.

Data synthesis and statistical analysis: We conducted a qualitative synthesis of results for selected articles. A Meta-analysis also performed for selected studies that provided a comparable classification of the outcome and determinants of interest.

The effect size of the Meta-analysis was performed for the utilization of postnatal care in Ethiopia. The determinants of postnatal care utilization were examined for the studies that met the Meta-analysis eligibility criteria. For example, if at least two studies were reported about one determinant of postnatal care use in common with their measure of effect and 95\% confidence interval $(\mathrm{CI})$.

The association between postnatal care service utilization and its determinant was estimated by calculating estimate effect size and $95 \%$ confidence interval (CI). A random effects model based on DerSimonian-Laird method (18) was used to account for variations between the studies as well as within the studies. The use of a random effect model was justified by the assumption that a true effect varies from study to study and normally distributed.

Additionally, the heterogeneity was separately estimated using a $\chi^{2}$ test, to get $\mathrm{Q}$ statistics with corresponding $\mathrm{p}$ values, and $I^{2}$ statistics. Heterogeneity or variation across studies was assessed using cut off point $\mathrm{I}^{2} \geq 50 \%$ (19). We assessed publication bias in Meta-analysis with funnel plot qualitatively, and Begg's test and Egger's test $(p<0.05)$ to consider statistical significance (20). Statistical analysis was conducted using STATA version 12. The results are presented using tables and forest plots with measures of effect and 95\% confidence interval.

Sensitivity and subgroup analysis: We explored possible sources of heterogeneity using sensitivity

DOI: http://dx.doi.org/10.4314/ejhs.v28i5.16 
analysis of quality studies. The effect of aberrant studies was examined via sensitivity analyses after the exclusion of studies with low and poor quality, as the classified by the quality scoring system (B and C class studies). Subgroup analysis was also performed for prevalence by place of study and region.

\section{RESULTS}

Study selection and data extraction: The literature search identified a total of 406 (75 from EMBASE, 114 from ISI Web of Sciences, 67 from PubMed, 146 from Scopus and 4 from Grey literature) potentially relevant articles. After removing 177 duplicates, 229 abstracts remained. Then, 215 articles were excluded after reading the titles and abstracts because of obvious irrelevance. Out of the 14 full-text articles retrieved and carefully evaluated, 5 were excluded as they did not meet inclusion criteria. For example, three of them do not have measure of association, one does not have full-text and the remain one is conference abstract. Finally, nine studies $(9,22-29)$ were included in the Metaanalysis. The flow diagram of studies identified for systematic review and Meta-analysis is shown in detail in Figure 1.

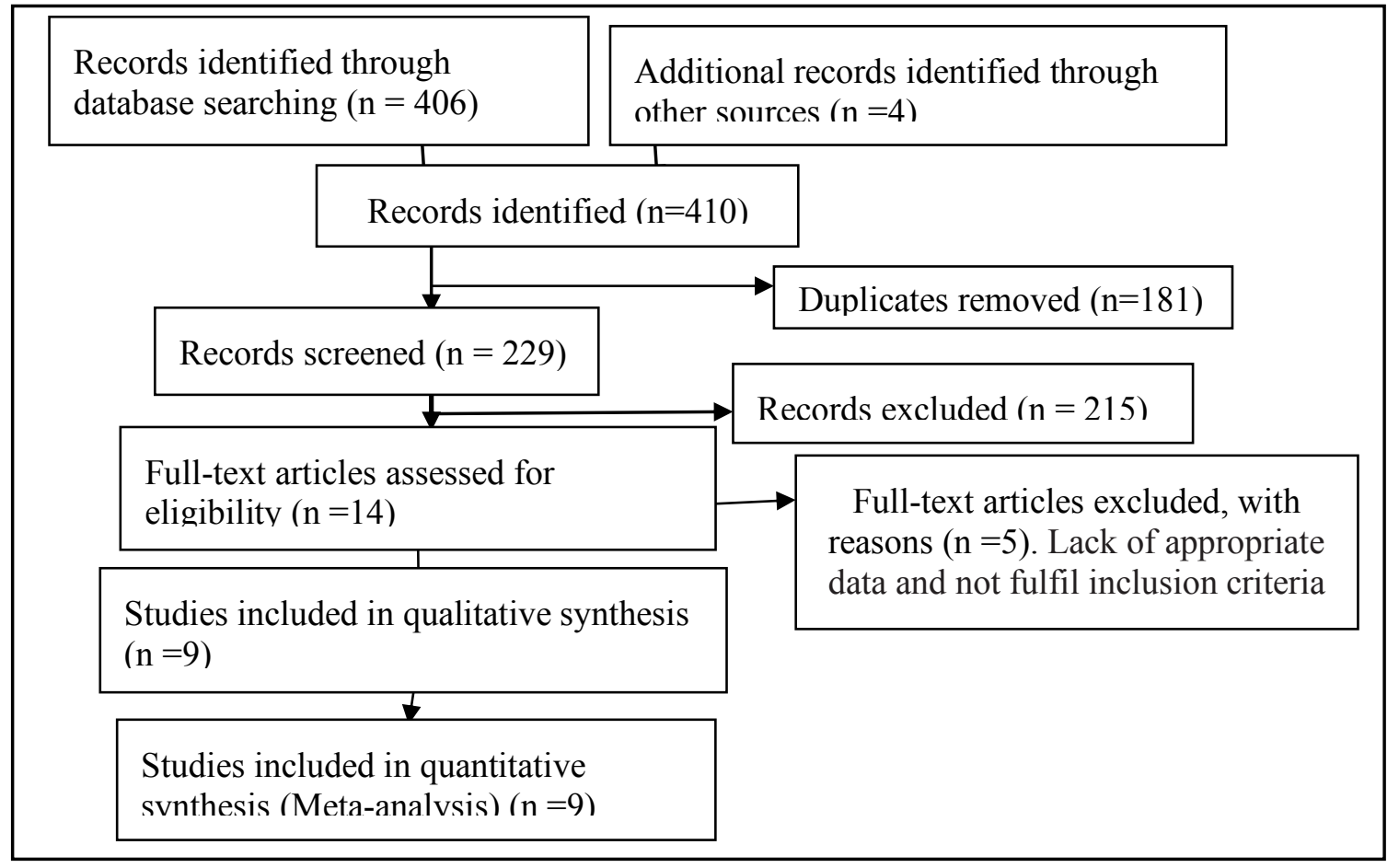

Figure 1: PRISMA flow diagram through the different phases of the systematic review and meta-analysis.

Characteristics of the studies: Overall, this systematic review included 14,557 study participants with a range of 561 to 7,908 in individual studies, and studies were carried out from 2011 to 2015. All participants were females in the reproductive age range, between 15 and 49 years.

Utilization of postnatal care services: The reported utilization of PNC service from included studies ranged between $6.3 \%$ and $66.8 \%$ (Table 1). The pooled estimate for utilization of PNC services from the nine studies included in this systematic review was 32\% (95\% CI: $21 \%, 43 \%$ ). There was high and significant heterogeneity between studies $\left(\mathrm{I}^{2}=99.67 \%\right.$; $\mathrm{p}$-value $\left.=0.00\right)$, indicating great variability in utilization across studies (Figure 2). Therefore, in order to identify the source of heterogeneity, we performed subgroup analysis based on place of studies (rural,

DOI: http://dx.doi.org/10.4314/ejhs.v27i8.16 
urban and both), and region (Central, Northern, Southern, Eastern Ethiopia, and countrywide), and after subgroup analysis heterogeneity was removed with $\mathrm{I}^{2}=$ zero percent for both subgroups. The utilization and 95\% confidence interval for subgroup analysis are shown in Table 2. For publication bias in the utilization of the service, Egger's test showed p-value equal to 0.168 , indicating there that was no potential publication bias.

Sensitivity analysis using only quality studies: Sensitivity analyses were performed by removing data from the Meta-analytic using random model in order to examine the influence of low quality and high-bias-risk studies on the overall utilization estimate. According to the quality score, only studies of higher quality (seven studies out of nine studies) were included in the sensitivity analyses. The sensitivity analyses resulted that the utilization of PNC services was (33\%; 95\% CI $(15 \%, 50 \%)$; $\left.\mathrm{I}^{2}=99.64 \%, \mathrm{p}=0.00\right)$. The utilization estimate after the sensitivity analysis lay within the $95 \%$ CI of the combined analysis, indicating that low-quality studies had no excessive influence on the pooled utilization estimate (Figure 3).

Table 1: Summary of main characteristics of the included studies

\begin{tabular}{|c|c|c|c|c|c|c|c|}
\hline SN & $\begin{array}{l}\text { Author and Year } \\
\text { of Publication }\end{array}$ & Study Area & $\begin{array}{l}\text { Place } \\
\text { setting }\end{array}$ & Study Design & $\begin{array}{l}\text { Sample } \\
\text { size }\end{array}$ & Age & $\begin{array}{l}\text { Quality } \\
\text { Score }\end{array}$ \\
\hline 1 & Worku et al., 2013 & North Gondar & Rural & Cross sectional & 1668 & $28.2 \pm 6.6$ & 8 \\
\hline 2 & Tesfaye S et al., 2014 & $\begin{array}{l}\text { Oromia } \quad \& \\
\text { Amhara }\end{array}$ & Rural & Cross sectional & 958 & $15-49$ & 6 \\
\hline 3 & Tesfahun et al., 2014 & Gondar Zuria & Both & Cross sectional & 820 & $28.3 \pm 7.71$ & 10 \\
\hline 4 & Tarekegn et al., 2014 & Country wide & Both & Cross sectional & 7908 & $15-49$ & 7 \\
\hline 5 & Lakew Y et al., 2016 & Hadiya & Rural & Cross sectional & 728 & $27.9 \pm 7.23$ & 10 \\
\hline 6 & Kifle D et al., 2017 & Haramaya & Rural & Cross sectional & 561 & $>15$ & 9 \\
\hline 7 & Dutamo, et al., 2015 & Hossaina & Urban & Cross sectional & 623 & $27.8 \pm 5.26$ & 10 \\
\hline 8 & Darega B, et al, 2016 & Gindberat & Rural & Cross sectional & 703 & $31.5 \pm 7.34$ & 10 \\
\hline \multirow[t]{12}{*}{9} & Limenih, et al., 2016 & Deberamorkos & Urban & Cross sectional & 588 & $28.5 \pm 4.6$ & 8 \\
\hline & Study & & & & & ES $(95 \% \mathrm{Cl})$ & $\begin{array}{l}\% \\
\text { Weight }\end{array}$ \\
\hline & Darega B. & & & & & $0.32(0.28,0.35)$ & 11.09 \\
\hline & Lakew $Y$. & & $\leftarrow$ & & & $0.18(0.15,0.21)$ & 11.13 \\
\hline & Tesfahun $\mathrm{F}$. & & & & $\rightarrow-$ & $0.67(0.64,0.70)$ & 11.10 \\
\hline & Worku A. G. & $\leftarrow$ & & & & $0.06(0.05,0.08)$ & 11.19 \\
\hline & Dutamo $\mathrm{Z}$. & & & $\longrightarrow$ & & $0.51(0.47,0.55)$ & 11.05 \\
\hline & Tarekegn S. M. & - & & & & $0.09(0.09,0.10)$ & 11.19 \\
\hline & Tesfaye S. & & & $\rightarrow$ & & $0.49(0.46,0.52)$ & 11.10 \\
\hline & Kifle D. & & 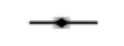 & & & $0.23(0.19,0.26)$ & 11.09 \\
\hline & Limenith M. A. & & & & & $0.34(0.30,0.37)$ & 11.06 \\
\hline & Overall $\left(1^{\wedge} 2=99\right.$ & $\%, p=0.00)$ & & & & $0.32(0.21,0.43)$ & 100.00 \\
\hline-.5 & & 1 & & .5 & & & $T_{1}$ \\
\hline
\end{tabular}

Figure 2: Forest plot for prevalence of PNC services utilization

Table 2: Subgroups analysis of prevalence of PNC Services Utilization by place of studies, region and sample size

DOI: http://dx.doi.org/10.4314/ejhs.v28i5.16 


\begin{tabular}{lllll}
\hline Subgroups & Subtotals(n) & $\begin{array}{r}\text { Number of } \\
\text { studies }\end{array}$ & Prevalence (95\% CI) & $\mathrm{I}^{2}(\%)$ \\
$\begin{array}{l}\text { Place of studies } \\
\text { Rural }\end{array}$ & 4618 & 5 & $0.14(0.14,0.15)$ & 0 \\
Urban & 1211 & 2 & $0.42(0.39,0.45)$ & 0 \\
Both & 8728 & 2 & $0.12(0.11,0.12)$ & 0 \\
Region of studies & & & & \\
Country wide & 8866 & 2 & $0.11(.10,0.12)$ & 0 \\
Central & 703 & 1 & $0.32(0.28,0.35)$ & 0 \\
Southern & 1351 & 2 & $0.29(0.27,0.31)$ & 0 \\
Northern & 3076 & 3 & $0.15(0.14,0.16)$ & 0 \\
Eastern & 561 & 1 & $0.23(0.19,0.26)$ & 0 \\
Overall & 14,557 & & $0.13(0.13,0.14)$ & 0 \\
\hline
\end{tabular}

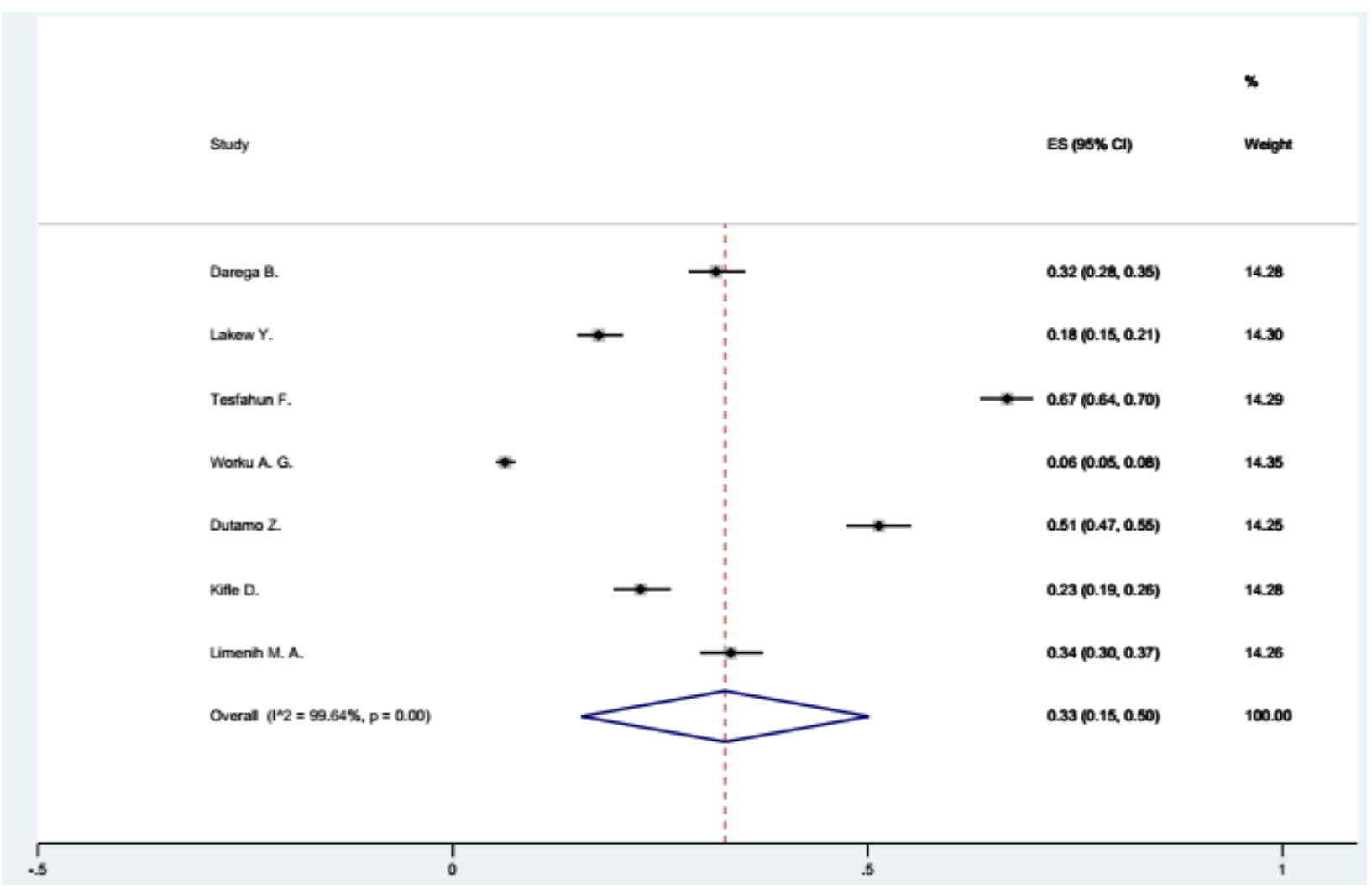

Figure 3: Forest plot for sensitivity analysis using only quality studies

Determinants of postnatal care service utilization: Table 3 shows a summary of the data extracted for the determinant of PNC service utilization. Nine studies were included for the Meta-analysis of determinants of postnatal care services utilization Thirteen key determinants were identified with the pooled odds ratio ranging from 1.44 to 5.75 (maternal education primary to secondary or above). These determinants were the ability of the mother to make decisions, number of ANC visit, having a history of ANC utilization, monthly income, wealth quintile, place of

DOI: http://dx.doi.org/10.4314/ejhs.v27i8.16 
residence, service provider, and knowledge and awareness of obstetric danger signs.

Utilization of postnatal care services was higher among women who had two or more ANC visits compared to women making none visits $\left(\mathrm{OR}=1.84 ; 95 \% \mathrm{CI}: 1.28,2.40 ; \mathrm{I}^{2}=0\right)$. Similarly, utilization of postnatal care services among women who had knowledge and awareness of obstetric danger sign is higher compared to those who did not have knowledge and awareness $\left(\mathrm{OR}=2.43 ; 95 \%\right.$ CI: $\left.1.71,3.15 ; \mathrm{I}^{2}=20.4\right)$. Mothers who had the ability to make decision were nearly two times more likely to use postnatal care than women waiting others for decision making $\left(\mathrm{OR}=1.89 ; 95 \% \mathrm{CI}: 1.25,2.54 ; \mathrm{I}^{2}=0\right)$. Women with husband with secondary or above education were more likely to use PNC service than those with a husband with informal or no education $\left(\mathrm{OR}=1.76 ; 95 \% \mathrm{CI}: 1.28,2.23 ; \mathrm{I}^{2}=0\right)$, as were richer women $(\mathrm{OR}=1.92 ; 95 \% \mathrm{CI}: 1.36,2.48$; $\mathrm{I}^{2}=0.0$ ). Moreover, women with middle household monthly income were more likely to use PNC service than those with lower monthly income $\left(\mathrm{OR}=1.60 ; 95 \% \mathrm{CI}: 1.13,2.07 ; \mathrm{I}^{2}=0\right)$, as were women from an urban area $(\mathrm{OR}=2.61 ; 95 \% \mathrm{CI}$ : $\left.1.96,3.26 ; \mathrm{I}^{2}=0\right)$.

Table 3: Summary of Data extracted for determinants by study

\begin{tabular}{|c|c|c|c|c|c|c|c|c|c|c|c|}
\hline \multirow[b]{2}{*}{$\begin{array}{c}\text { Authors and Year of } \\
\text { Pulication }\end{array}$} & \multicolumn{11}{|c|}{ Determinants } \\
\hline & 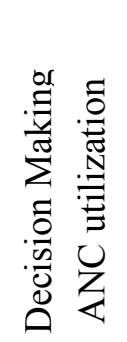 & 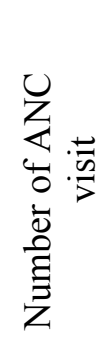 & 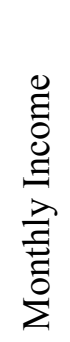 & 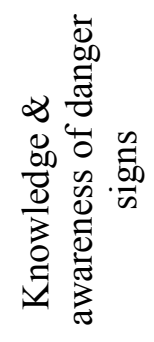 & 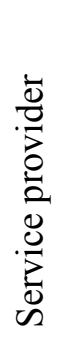 & 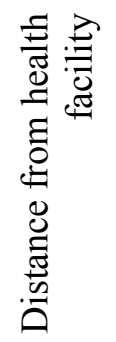 & 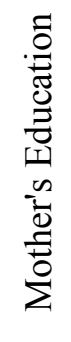 & 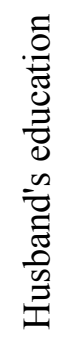 & 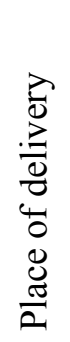 & 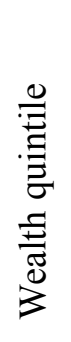 & 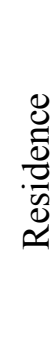 \\
\hline Worku A.G et al. (2013) & $\sqrt{ }$ & & $\sqrt{ }$ & & $\sqrt{ }$ & & & & & $\sqrt{ }$ & \\
\hline Darega B. et al (2016) & $\sqrt{ } \sqrt{ }$ & & & & & $\sqrt{ }$ & & & $\sqrt{ }$ & & \\
\hline Kifle D. et al. (2017) & & & & $\sqrt{ }$ & & & & $\sqrt{ }$ & $\sqrt{ }$ & & \\
\hline Tesfahun. F. et al (2017) & $\sqrt{ }$ & $\sqrt{ }$ & & & & $\sqrt{ }$ & & & $\sqrt{ }$ & & $\sqrt{ }$ \\
\hline Limenih M. et al (2016) & & & & $\sqrt{ }$ & & & & & $\sqrt{ }$ & & \\
\hline Tarekegn S. et al. (2014) & $\sqrt{ }$ & & & & & & $\sqrt{ }$ & $\sqrt{ }$ & & $\sqrt{ }$ & $\sqrt{ }$ \\
\hline Tesfaye S. et al (2014) & $\sqrt{ }$ & & & & $\sqrt{ }$ & & $\sqrt{ }$ & & & & \\
\hline Lakew Y. et al .(2016) & & $\sqrt{ }$ & & $\sqrt{ }$ & & $\sqrt{ }$ & $\sqrt{ }$ & $\sqrt{ }$ & & & \\
\hline Dutamo Z. et al (2015) & & $\sqrt{ }$ & $\sqrt{ }$ & $\sqrt{ }$ & & & & & & & \\
\hline
\end{tabular}

Women who got another maternal care (like delivery service or ANC) by skilled personnel were three times more likely to use PNC service compared to those who received the service from untrained or none $(\mathrm{OR}=3.16$; 95\% CI: $1.62,4.70$; $\mathrm{I}^{2}=32.9$ ), as were women who gave delivery at health facility than who those gave birth at home $\left(\mathrm{OR}=2.13 ; 95 \% \mathrm{CI}: 1.14,3.12 ; \mathrm{I}^{2}=37.9\right)$. Women with a history of ANC visit were two and half times more likely to use PNC services than those who did not have the history $(\mathrm{OR}=2.55 ; 95 \% \mathrm{CI}$ : $1.42,3.68)$, with high variation among studies $\left(\mathrm{I}^{2}\right.$ $=80.9 \%$,). There was no association between use of PNC services and mothers' education in both at primary and secondary level compared to informal or no education. We observed that there was high heterogeneity between studies $\left(\mathrm{I}^{2}=\right.$ 70.9\%) (Figure 4).

DOI: http://dx.doi.org/10.4314/ejhs.v28i5.16 


\begin{tabular}{|c|c|c|c|c|c|c|c|}
\hline Determinants & Comparison & $\begin{array}{l}\text { \# of } \\
\text { studies }\end{array}$ & $\begin{array}{l}\text { Total } \\
\text { sample }\end{array}$ & & ES (95\% Cl) & $\begin{array}{l}\text { P-value } \\
\text { Z-statistic }\end{array}$ & $\begin{array}{l}\text { I-square } \\
\%\end{array}$ \\
\hline Decision Making & Mother (vs. other) & 2 & 1523 & $\leftarrow$ & $1.89(1.25,2.54)$ & .712 & 0 \\
\hline ANC utilization & Yes (vs no) & 4 & 11237 & - & $2.55(1.42,3.68)$ & .001 & 80.9 \\
\hline \# of ANC visit & $2+$ (vs none) & 4 & 2171 & $\bullet$ & $1.84(1.28,2.40)$ & .469 & 0 \\
\hline Monthly Income & Middle (vs lower) & 2 & 2291 & $\bullet$ & $1.60(1.13,2.07)$ & .787 & 0 \\
\hline $\begin{array}{l}\text { Knowledge \& awamess } \\
\text { of danger signs }\end{array}$ & Yes (vs no) & 4 & 2500 & $\leftarrow$ & $2.43(1.71,3.15)$ & .288 & 20.4 \\
\hline Service provider & $\begin{array}{l}\text { Skilled (vs } \\
\text { untrained/none) }\end{array}$ & 2 & 2626 & 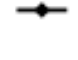 & $3.16(1.62,4.70)$ & .222 & 32.9 \\
\hline $\begin{array}{l}\text { Distance from } \\
\text { health facility }\end{array}$ & $15 \mathrm{~km}(\mathrm{Vs}>5 \mathrm{~km})$ & 3 & 2251 & $\leftarrow$ & $2.32(1.63,3.01)$ & .787 & 0 \\
\hline $\begin{array}{l}\text { Mother's } \\
\text { Education }(P)\end{array}$ & $\begin{array}{l}\text { Primary (Vs } \\
\text { informal/none) }\end{array}$ & 3 & 9594 & $\bullet$ & $1.44(0.97,1.90)$ & .121 & 52.6 \\
\hline $\begin{array}{l}\text { Mother's } \\
\text { education (S) }\end{array}$ & $\begin{array}{l}\text { secondary \& above } \\
\text { (vs informal/none) }\end{array}$ & 2 & 8636 & & $5.75(-3.07,14.58)$ & .064 & 70.9 \\
\hline Husband's education & $\begin{array}{l}\text { secondary \& above } \\
\text { (Vs Informal/none) }\end{array}$ & 3 & 9197 & $\bullet$ & $1.76(1.28,2.23)$ & .613 & 0 \\
\hline Place of delivery & $\begin{array}{l}\text { Health } \\
\text { institution (Vs home) }\end{array}$ & )$^{4}$ & 2672 & $\rightarrow$ & $2.13(1.14,3.12)$ & .185 & 37.9 \\
\hline Wealth quintile & Richer (vs poorest & 2 & 9576 & $\leftarrow$ & $1.92(1.36,2.48)$ & .839 & 0 \\
\hline Residence & Urban (Vs Rural) & 2 & 8728 & $\leftarrow$ & $2.61(1.96,3.26)$ & .934 & 0 \\
\hline & & & $\begin{array}{c}1 \\
-14.6\end{array}$ & & & & \\
\hline
\end{tabular}

Figure 4: Forest plot of odds ratios of determinants of postnatal care services use with corresponding 95\% CI assessed in 9 studies with quantitative data

\section{DISCUSSION}

We systematically reviewed studies assessing utilization and determinants of PNC services in Ethiopia. In this study, we found that the utilization of postnatal care services in Ethiopia was 32\% (95\% CI: $21 \%, 43 \%)$ among the studies included. However, the utilization of PNC services reported by Ethiopian DHS 2016 was $17 \%$ (2). The difference might be due to the fact that DHS 2016 reported only on those mothers who received the services in the first 2 days after birth while our study included all those receiving the service with 42 days after birth.

We found strong evidence indicating that the use of postnatal care service was relatively high among women who received service from a skilled service provider, had a history of ANC utilization, were from an urban area, had access to a health facilityin less than $5 \mathrm{~km}$ and gave birth in health facilities.

ANC use, the number of ANC visits, health service provided by a skilled provider, health facility delivery, and having knowledge and awareness of obstetric danger signs were found to play a role in PNC services use. This can be due to familiarity with health services and encouragement by health workers $(7,8)$.

Mothers who had the power of decision making were more likely to use PNC service which could be associated with women's autonomy and control over resources. Educated husbands may be aware of the benefit of the PNC and more able to communicate with health

DOI: http://dx.doi.org/10.4314/ejhs.v27i8.16 
workers, demand appropriate care, and may put fewer constraints on their wives' decision making, thus facilitating PNC services seeking and utilization (7).

We found strong evidence that the use of PNC services was relatively high among women with high quintile index (richer) and among urban women. This is because women with high quintile index belong to households who can afford the medical and non-medical cost of PNC $(7,8)$,

In this study, there was no association between use of a PNC services and mothers' education in both at primary level and secondary level compared to informal or no education with higher variation among studies. However, mothers' education was found to has a significant association with postnatal care use in other literature review. Such a difference might arise due to the high variation observed among studies which reported on maternal education in this study, the small sample size in the studies and lack of uniform categorization of maternal educational level (7).

This study has certain limitations. First, because only cross-sectional studies were found during literature searching, we cannot conclude the temporal relationship between identified determinants and PNC service utilization. Second, although we extracted the adjusted ORs that reflected the greatest degree of control for potential confounders, the confounders controlled for were not known among studies. Third, the results can only be a representative inference of all studies published, but not included. Nevertheless, there was no evidence of publication bias. Therefore, these results are important in guiding the assessment of the current evidence on the prevalence and determinants of PNC service utilization in Ethiopia. They are also important for the definition of future research strategies and public health policy decisions.

In conclusion, the results from this Metaanalysis of the literature demonstrate that ANC utilization, skilled service provider, living in urban area, delivery in a health facility, proximity to a health facility and knowledge about obstetric danger signs had significant apositive effects on postnatal care utilization. As opposed to other studies, mothers' education was not significantly associated with postnatal care utilization. Therefore, more rigorous studies should be conducted to identify the determinants with causal associations with postnatal care service utilization.

\section{REFERENCES}

1. Lawn JE, Blencowe H, Kinney MV, Bianchi F, Graham WJ. Evidence to inform the futur of maternal and newborn health. Best Practice \& Research Clinical Obstetrics \& Gynaecology. 2016; 36:169-183.

2. CSA. Ethiopia Demographic and Health Survey 2016:Key Indicators Report. Addis Ababa, Ethiopia, and Rockville, Maryland, USA. CSA and ICF.

3. World Health Organization. WHO technical consultation on postpartum and postnatal care. WHO

2017/03/17/20:52:34;http://www.who.int/maternal _child_adolescent/documents/WHO_MPS_10_03/ en

4. World Health Organization. WHO recommendations on the postnatal care of the mother and newborn. WHO 2017/03/17/21:01:36; http://www.who.int/maternal child_adolescent/documents/postnatalcarerecom mendations/en/. Accesed 15 April 2017

5. Van Lerberghe W, V. De Brouwere. Ofblind alleys and things that have worked:history's lessons on reducing maternal mortality. Safe motherhood strategies: a review of the evidence, 2000.

6. Khanal V, Adhikari M, Karkee R, Gavidia T.Factors associated with the utilization ofpostnatal care services among the mothers of Nepal: analysis of Nepal Demographic and Health Survey 2011. BMC Women's Health. 2014;14:19.

7. Gabrysch S, O.M.R. Campbell. Still too far to walk: Literature review of the determinants of delivery service use. BMC Pregnancy and Childbirth. 2009; 9: 34.

8. Say L, R. Raine. A systematic review of inequalities in the use of maternal health care in developing countries: examining the scale of the problem and the importance of context. Bulletin of the World Health Organization. 2007; 85(10):812.

9. Limenih MA, Endale ZM, and BA. Dachew. Postnatal Care Service Utilization and Associated Factors among Women Who Gave Birth in the Last 12 Months prior to the Study in Debre

DOI: http://dx.doi.org/10.4314/ejhs.v28i5.16 
Markos Town, Northwestern Ethiopia: A Community-Based Cross-Sectional Study. International Journal of Reproductive Medicine. 2016; http://dx.doi.org/10.1155/2016/7095352.

10. Mohan D, Gupta S, LeFevere A, Bazant E, Killewo J, Baqui AH. Determinants of postnatal care use at health facilities in rural Tanzania:a multilevel analysis of a household survey. BMC pregnancy and childbirth. 2015; 15(1):282.

11. Titaley CR, M.J. Dibley, C.L. Roberts. Factors associated with non-utilisation of postnatal care services in Indonesia. Journal of Epidemiology \& Community Health. 2009; 63(10):827-831.

12. Yeneabat T. Factors associated with non utilization of postnatal care in Ankesha Guagusa Woreda, Awi Zone, Northwest Ethiopia: a cross sectional study. Tropical Medicine \& International Health. 2015;20.

13. Malonga F, M. Dramaix-Wilmet, P. Donnan. Determinants of maternal health services utilization in urban settings of the Democratic Republic of Congo-a case study of Lubumbashi City. BMC pregnancy and childbirth. 2012;12(1).

14. Singh A, Padmada SS, Mishra US, Pallikadavth S, Johnson FA, Mattews Z. Socio economic inequalities in the use of postnatal care in India. PloS one. 2012;7(5):e37037.

15. Moher D, Liberati A, Tetzlaff J, Altman DG. Preferred reporting items for systematic reviews and meta-analyses: the PRISMA statement. PLoS Med. 2009;6(7):e1000097.

16. Lien N, Henriksen HB, Nymoen LL, Wind M, Klepp KI. Availability of data assessing the prevalence and trends of overweight and obesity among European adolescents. Public health nutrition. 2010; 13(10A) :1680-1687.

17. Wells G. SBOD. The Newcastle-Ottawa Scale (NOS) for Assessing the Quality of non randomised Studies in Meta-analysis. in Proceedings of the Third Symposium on Systematic Reviews beyond the Basics. 2000.

18. DerSimonian R, N. Laird. Meta-analysis in clinical trials. Controlled clinical trials. 1986; 7(3):177-188.

19. Higgins JP, Thompson SG, Deeks JJ, Alma DG. Measuring inconsistency in meta-analyses. British medical journal. 2003; 327.

20. Egger M, G. Davey-Smith, D. Altman. Systematic reviews in health care: meta analysis in context. 2008: John Wiley \& Sons.
21. Duval S, R. Tweedie. Trim and fill: a simple funnel-plot-based method of testing and adjusting for publication bias in meta-analysis. Biometrics. 2000; 56(2):455-463.

22. Worku AG, Yalew AW, Afework MF. Factors affecting utilization of skilled maternal care in Northwest Ethiopia: A multilevel analysis. $B M C$ International Health and Human Rights. 2013; 13(1):20.

23. Tesfaye S, Barry D, Gobezayehu AG, et al. Improving coverage of postnatal care in rural Ethiopia using a community-based, collaborative quality improvement approach. Journal of Midwifery and Women's Health. 2014; 59(s1):s55.

24. Tesfahun F, Worku W, Mazengiya F, Kifle M. Knowledge, perception, and utilization of postnatal care of mothers in Gondar Zuria District, Ethiopia: a cross-sectional study. Maternal and child health journal. 2014; 18(10):2341-2351.

25. Tarekegn SM, LS. Lieberman, V. Giedraitis. Determinants of maternal health service utilization in Ethiopia: Analysis of the 2011 Ethiopian Demographic and Health Survey. BMC Pregnancy and Childbirth. 2014;14(1):161.

26. Lakew Y, Tessema F, Hailu C. Birth Preparedness and Its Association with Skilled Birth Attendance and Postpartum Checkups among Mothers in Gibe Wereda, Hadiya Zone, South Ethiopia. Journal of Environmental and Public Health. 2016; http://dx.doi.org/10.1155/2016/6458283

27. Kifle D, Azale T, Gelaw YA, Melsew YA. Maternal health care service seeking behaviors and associated factors among women in rural Haramaya District, Eastern Ethiopia: a triangulated community-based cross-sectional study. Reproductive Health. 2017; 14(1):1-11.

28. Dutamo Z, Assefa N, Egata G. Maternal health care use among married women in Hossaina, Ethiopia. BMC Health Serv Res. 2015; 15(1):365.

29. Darega B, Dida N, Tafese F, Ololo S. Institutional delivery and postnatal care services utilizations in Abuna Gindeberet District, West Shewa, Oromiya Region, Central Ethiopia: A Community-based cross sectional study. BMC Pregnancy and Childbirth. 2016;16(149):1-7.

30.

DOI: http://dx.doi.org/10.4314/ejhs.v27i8.16 